\title{
Short communication: The effect of diarrhea and navel inflammation on the lying behavior of veal calves
}

\author{
M. J. Studds, ${ }^{*}$ L. L. Deikun, ${ }^{*}$ † D. E. Sorter, ${ }^{*}$ J. A. Pempek, ${ }^{*}$ and K. L. Proudfoot ${ }^{* 1}$ \\ *Veterinary Preventive Medicine, The Ohio State University, Columbus 43210 \\ †Provimi, Brookville, OH 45309
}

\begin{abstract}
Many veal calves arrive to growing facilities with diseases, including diarrhea and navel inflammation. Observing neonatal calf behavior, such as lying behavior, can be used to better detect and determine the implications of these diseases. The aim of this study was to determine the effect of navel inflammation and diarrhea on lying behavior in neonatal veal calves. This study was part of a larger experiment that included a total of 360 male Holstein calves from 3 cohorts; from these calves, we selected a subset of 125 calves (every third calf as they entered the barn) to be fitted with 3-dimensional accelerometers (Hobo Pendant G data loggers; Onset Computer Corp., Bourne, MA) on 1 hind leg to continuously measure lying time, number of lying bouts, and lying bout duration. Calves were housed individually on slatted flooring (Tenderfoot; Tandem Products Inc., Minneapolis, MN) in 3 rooms of a mechanically ventilated barn. Health exams were conducted twice weekly for 2 wk starting the day after arrival. Exams included rectal temperature, navel score $(0=$ normal, $1=$ mildly inflamed, $2=$ moderately inflamed, 3 = severely inflamed), and fecal score $(0$ $=$ normal, $1=$ semiformed, $2=$ loose, 3 = watery). Calves were considered to have navel inflammation (n $=22)$ or diarrhea $(\mathrm{n}=15)$ if they scored $\geq 2$ during at least 3 of the 4 health exams. The lying behavior of these calves was compared with that of normal calves $(\mathrm{n}=18)$ that had no signs of illness and rectal temperatures $<39.4^{\circ} \mathrm{C}$ during at least 3 of the 4 health exams. Data were analyzed using a repeated-measures ANOVA; models included cohort (1, 2, or 3$)$, health status (normal, navel inflammation, or diarrhea), week (1 or 2), and a health by week interaction. There was an effect of health status on lying time, whereby normal calves spent more time lying compared with calves with
\end{abstract}

Received May 2, 2018.

Accepted August 23, 2018.

${ }^{1}$ Corresponding author: Proudfoot.18@osu.edu inflamed navels and tended to spend more time lying compared with calves with diarrhea. There was no effect of health status on the number of lying bouts per day or on the duration of lying bouts. There were no health by week interactions. Results indicate that neonatal veal calves with navel inflammation and diarrhea may be less comfortable than calves without these conditions. Veal producers should consider adapting their facilities to create more comfortable lying environments to help calves better recover from disease, such as by adding a hospital pen with comfortable bedding.

Key words: sickness behavior, housing, calf comfort

\section{Short Communication}

Male neonatal calves used for veal are highly susceptible to disease in early life. Two recent studies in North America have found that approximately 13 to $14 \%$ of calves arrive at growing facilities with diarrhea and that 26 to $27 \%$ arrive with abnormal or inflamed navels (Pempek et al., 2017; Renaud et al., 2018). At growing facilities, calves are often housed in individual pens with hard, slatted floors, presenting challenges for calf comfort. The effect of diseases such as diarrhea and inflamed navels on calf comfort in this type of environment is not well understood.

Researchers have determined that disease can affect cow comfort and behavior in dairy cows and calves (Borderas et al., 2008; Cyples et al., 2012; Fogsgaard et al., 2012). For example, dairy calves injected with bacterial endotoxin (LPS) spent more time lying inactively compared with calves that were injected with saline (Borderas et al., 2008). This increase in lying time and inactivity is thought to help the animal conserve energy to mount an immune response (Hart, 1988). Conversely, in adult cattle, bacterial infections that cause mastitis result in a decrease in lying time and increase in inactive standing time (Cyples et al., 2012; Fogsgaard et al., 2012), suggesting that pain associated with the disease may interfere with the cow's motivation to lie down and conserve energy. To our knowledge, no research has assessed the relationship between lying behavior and 
diseases common in veal calves, such as navel inflammation and diarrhea.

The objective of this study was to determine the effect of navel inflammation and diarrhea on lying behavior in neonatal veal calves 2 wk after arrival at the growing facility. We predicted that calves with diarrhea would spend more time lying to conserve energy and that calves with navel inflammation would spend less time lying due to pain associated with increased pressure on the navel.

The study was conducted in accordance with the Ohio State University's Institutional Animal Care and Use Committee (protocol no. 2015A00000108 and no. 2017A00000046). A total of 360 Holstein bull calves from a commercial veal growing facility in Ohio were included in a larger experiment from which a subset of 125 calves were selected for this study. Calves arrived at the facility in 3 cohorts of 120 calves (cohort 1 arrived in summer 2016, and cohorts 2 and 3 arrived in summer 2017). All calves were purchased from livestock auctions in the northeastern United States and were transported on 2-floor trailers with naturally ventilated sides and a sawdust bedding substrate to the growing facility in Ohio within approximately $1 \mathrm{wk}$ of life (actual age unknown).

Upon arrival at the growing facility, calves were housed individually in 3 rooms within a mechanically ventilated barn (1 room/cohort). Calves were kept in pens $(2.13 \mathrm{~m} \times 0.61 \mathrm{~m})$ with plastic-coated metal slatted flooring (Tenderfoot; Tandem Products Inc., Minneapolis, MN). Pens were partitioned using metal dividers with horizontal bars allowing visual and physical nose-to-nose contact between neighboring calves. Calves were fed milk replacer twice daily using buckets using a proprietary step-up program and were provided water via a metal nipple watering system. Milk replacer was gradually increased from approximately 3 to $5 \mathrm{~kg} /$ calf per day from the first day they arrived to the end of the second week. Calves also had trough access to a corn, chopped straw, and pelleted feed ration starting $1 \mathrm{~d}$ after arrival.

On the day of arrival (cohort $1 ; \mathrm{n}=45$ calves) or the third day after arrival (cohorts 2 and $3 ; \mathrm{n}=40$ calves/ cohort), every third calf was fitted with a 3 -dimensional accelerometer (Hobo Pendant G data loggers; Onset Computer Corp., Bourne, MA) on 1 of their hind legs ( $\mathrm{n}=125$ calves across all 3 cohorts) using a plastic leg band and 3M VetWrap (3M, Maplewood, MN). This sample size was determined using a power analysis that included estimations of health effects from dairy cows and calves (Borderas et al., 2008; Cyples et al., 2012; Fogsgaard et al., 2012) and disease prevalence at arrival from previous studies on veal calves (Pempek et al., 2017; Renaud et al., 2018). We estimated needing least 12 calves in each health category and a total of 92 calves enrolled in the study to obtain this sample size; we intentionally recruited an additional 33 calves to ensure that we would obtain an adequate sample size for each health category after losses due to early mortalities or mechanical errors from the accelerometers. Every third calf was selected to account for potential confounders associated with the calves' location within the barn (e.g., air circulation, lighting). Accelerometers were not placed on calves if they were severely depressed at arrival (e.g., lying in lateral recumbency and showing difficulty standing). Accelerometers were fitted the third day after arrival for cohorts 2 and 3 because the research staff prioritized and conducted health assessments on $\mathrm{d} 1$ and 2 of the study.

Accelerometers measured lying time, the number of lying bouts, and lying bout duration at 1-min intervals (validated for use in calves by Bonk et al., 2013). Accelerometers were removed after 2 wk to offload the data onto a computer. Days with partial data (the day the logger was first affixed and the day the logger was removed) were removed before the final analysis. Full days of accelerometer data were collected from d 4 to 14 after arrival at the growing facility for calves in all 3 cohorts.

Health exams were conducted twice weekly for $2 \mathrm{wk}$ starting on the day after arrival for all calves. One experimenter for cohort 1 (postdoctoral researcher) and 3 experimenters (2 veterinary students and 1 master's student) for cohort 2 were trained by a veterinarian before the start of the experiment to improve interobserver consistency in health scoring. For cohorts 2 and 3 , the 3 experimenters scored the same calves for interobserver reliability until they reached sufficient agreement $\left(\mathrm{R}^{2} \geq 0.9\right)$. Health exams included rectal temperature, navel score [adapted from Fecteau et al., 1997: 0 = normal (pencil sized), $1=$ mildly inflamed (bigger than normal; approximately the width of the pointer finger), $2=$ moderately inflamed (bigger than normal; approximately the width of the pointer and middle fingers), $3=$ severely inflamed (bigger than normal; approximately the width of the pointer, middle, and ring fingers)], and a fecal score [McGuirk, 2008: 0 $=$ normal, $1=$ semiformed (pasty), $2=$ loose (stays on top of slatted floor), $3=$ watery (sifts through slatted floor)].

Data were analyzed using SAS version 9.4 (SAS Institute Inc, Cary, NC). Before analysis, lying time data were summarized by day for each calf from d 4 to 14 after arrival. Mean daily lying behavior data were then calculated across 2 approximate weeks after arrival (wk 1: d 4-9, wk 2: d 10-14). From the pool of 125 calves 
fitted with accelerometers, calves were included in the final analysis if they met one of the following criteria during at least 3 of the 4 health examinations: (1) navel inflammation (navel score $\geq 2$ ), (2) diarrhea (fecal score $\geq 2$ ), or $(3)$ normal with navel and fecal scores $<2$ and rectal temperature $<39.4^{\circ} \mathrm{C}$. We chose to exclude calves with high body temperatures because this is known to affect behaviors such as lying time (Hart, 1988).

Differences in daily lying time were determined by analyzing the number of lying bouts and lying bout duration of normal calves compared with those with navel inflammation or diarrhea. Data were analyzed using a repeated-measures ANOVA (PROC MIXED). Models included cohort $(1,2$, or 3 ) and health status (normal, navel inflammation, or diarrhea) as fixed effects, week (1 or 2 ) as a categorical repeated measure, and a health by week interaction. Repeated measures within calf were modeled using an autoregressive covariance structure chosen based on best fit using the Bayesian information criterion closest to zero. If health status was found to be statistically significant $(P<0.05)$, a post hoc Tukey's test was conducted to compare calves with different health status (normal vs. navel inflammation, normal vs. diarrhea, and navel inflammation vs. diarrhea). Statistical significance was declared at $P<0.05$, and statistical tendencies were declared at $P$ $<0.10$. Results are presented as least squares means \pm standard errors.

From the 125 calves fitted with accelerometers, 22 calves $(17.6 \%)$ met our criteria for inflamed navels, 15 calves $(11.2 \%)$ met our criteria for diarrhea, and 18 calves $(14.4 \%)$ met our criteria for normal. Seven $(38.9 \%)$ and $1(6.7 \%)$ of the calves with inflamed navels or diarrhea, respectively, had an elevated body temperature $\left(>39.4^{\circ} \mathrm{C}\right)$ during at least 1 health exam. Half $(\mathrm{n}=11)$ of the calves with inflamed navels had navel scores $\geq 2$ for 3 of the 4 health exams, and the remaining half $(\mathrm{n}=11$ ) had navel scores $\geq 2$ for all 4 health exams. Ten $(66.7 \%)$ of the calves with diarrhea had fecal scores $\geq 2$ for 3 of the 4 health exams, and the remaining $5(33.3 \%)$ had navel scores $\geq 2$ for all 4 health exams.

We detected an effect of health status on daily lying time $\left(F_{2,51}=3.68 ; P=0.03\right.$; Figure 1$)$; normal calves spent more time lying compared with calves with navel inflammation $(P=0.01)$ and tended to spend more time lying compared with calves with diarrhea across the 2 -wk period $(P=0.05)$. There was no difference in lying time between calves with navel inflammation and those with diarrhea $(P=0.74)$. Regardless of health status, calves spent less time lying during the second week after arrival compared with the first week $\left(F_{1,52}=\right.$ $7.02 ; P=0.01)$. There was no interaction between week and health status $\left(F_{2,52}=0.66 ; P=0.52\right)$.
We detected no effect of health status on the number $\left(F_{2,51}=1.03 ; P=0.37\right.$; Figure 1$)$ or duration $\left(F_{2,51}=\right.$ $0.49 ; P=0.62)$ of lying bouts across the 2 -wk period. There was also no effect of week on the number of lying bouts $\left(F_{1,52}=0.04 ; P=0.84\right)$ or lying bout duration $\left(F_{1,52}=0.63 ; P=0.43\right)$ and no week by health status interactions (lying bouts: $F_{1,52}=0.52, P=0.60$; lying duration: $\left.F_{1,52}=0.77, P=0.47\right)$.

The objective of this study was to determine differences in lying behavior between neonatal veal calves with navel inflammation, diarrhea, and no health problems (normal) during the first 2 wk after arrival at the growing facility. We found that calves with persistent navel inflammation or diarrhea spent less time lying compared with normal calves but showed no differences in lying bouts or bout duration.

Calves in our study with navel inflammation during the first $2 \mathrm{wk}$ after arrival at the veal facility spent less
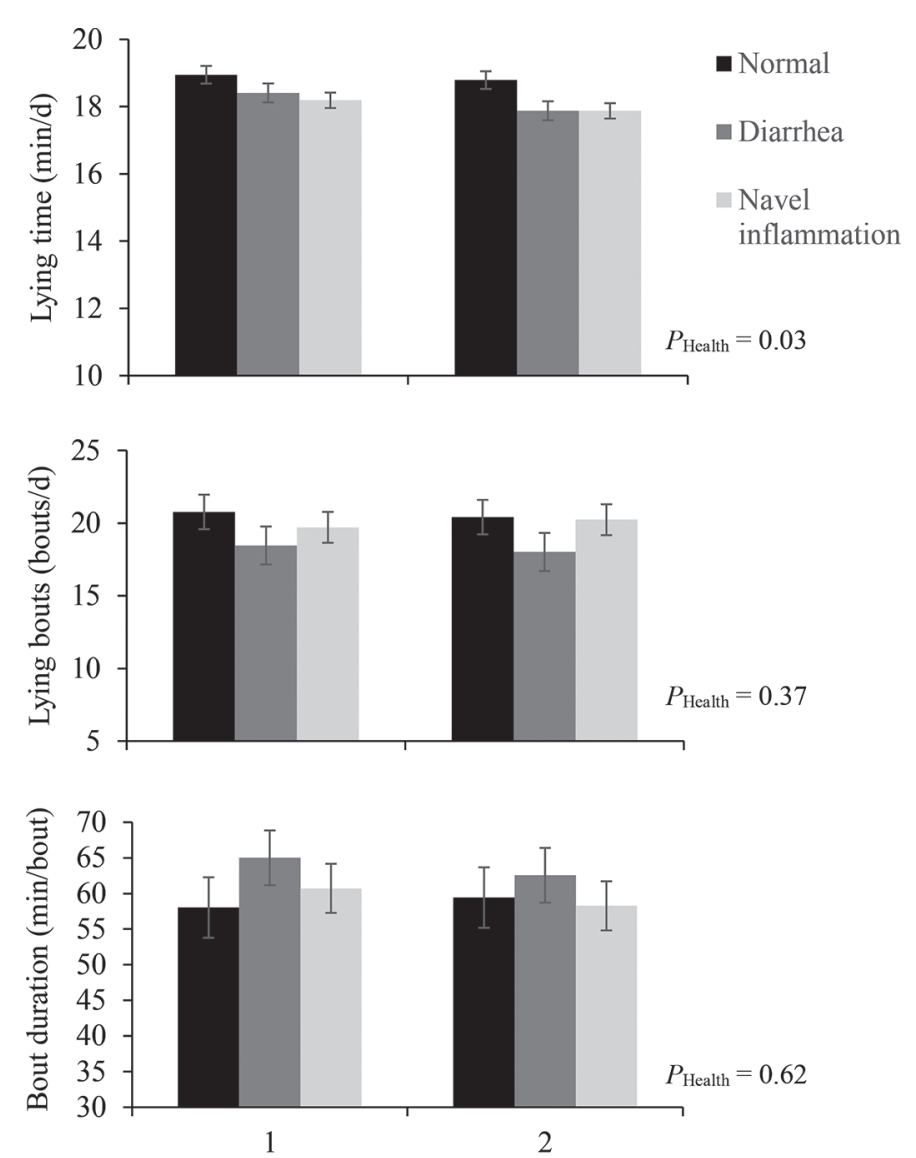

Week after arrival at growing facility

Figure 1. Least squares means $\pm \mathrm{SE}$ for daily lying time, number of lying bouts, and lying bout duration of male veal calves with navel inflammation, diarrhea, or no health problems ("normal") during the 2 wk after arrival at the veal growing facility. $P$-values signify main effects of health status. 
time lying compared with normal calves. Although no studies to our knowledge have investigated the effect of navel inflammation on lying behavior in calves, studies in adult dairy cows have shown that cows with mastitis, a painful inflammatory condition of the udder, spend less time lying compared with cows without mastitis (Medrano-Galarza et al., 2012) or compared with previous days when the cow had no mastitis (Cyples et al., 2012; Fogsgaard et al., 2012). Authors from these studies suggest that the pain associated with mastitis interferes with a cow's normal sickness behavior, such as lying down to conserve energy. Veal calves with navel inflammation may have similar experiences as dairy cows with mastitis, as both have inflammation in the caudal abdomen to pelvic area, thus making lying on either the udder or the navel potentially painful.

In contrast to our original hypothesis, calves with diarrhea during the first 2 wk after arrival at the veal facility tended to spend less time lying compared with normal calves. We had predicted that calves with diarrhea would spend more time lying compared with normal calves to conserve energy as part of a normal sickness behavior response. No research to our knowledge has assessed the effect of diarrhea on lying behavior in dairy or veal calves. However, Borderas et al. (2008) found that calves given a low dose of bacterial LPS showed characteristic sickness behaviors, including an increase in time spent lying inactive, an increase in lying bouts and bout duration, and decreases in rumination time, time spent eating hay, and time spent self-grooming. The calves included in the Borderas et al. (2008) study also developed a fever, which may have partially driven these behavioral changes. In our study, calves with diarrhea may not have had a fever, as we diagnosed diarrhea based on fecal score alone. Causes of calf diarrhea are multifactorial and may or may not be associated with a bacterial infection (McGuirk, 2008). Thus, the calves in our study with diarrhea may not have been experiencing a normal sickness response due to a lack of infection associated with the diarrhea.

It remains unclear why calves with diarrhea in our study tended to spend more time standing compared with normal calves. Calves were housed on a metal slatted flooring, which may have become wet and slippery for calves with loose feces, affecting the calves' motivation to lie down. Although no work has been done with veal calves, dairy calves show a preference for dry sawdust bedding over wet sawdust or bare concrete (Camiloti et al., 2012). Adult dairy cows also show a clear preference for a dry lying surface and will even spend their time standing outside a stall when only wet bedding is available (Fregonesi et al., 2007). Thus, the veal calves with diarrhea in our study may have avoided lying down due to a wet lying surface.
The results of our study provide veal producers with information about the comfort of their calves experiencing health problems upon arrival at their facilities. Our results indicate that calves that arrive at the growing facility with diarrhea and navel inflammation may be less comfortable in their environment compared with calves that arrive without these health problems. A reduction in lying time may interfere with disease recovery (Hart, 1988; Johnson, 2002); thus, producers should consider creating more comfortable environments for ill calves upon arrival. Although research is needed in veal calves, studies with dairy heifer calves have shown that calves prefer soft surfaces (e.g., dry sawdust, wood, or long-cut straw bedding) to concrete or slatted lying surfaces (Stefanowska et al., 2002; Camiloti et al., 2012; Worth et al., 2015). Veal calf producers may consider these more comfortable bedding options for their sick calves.

A main limitation of the study was the sampling method for health exams; sampling calves twice weekly instead of daily means that we may not have observed the first day that a disease bout occurred. Also, due to the transient nature of diseases such as diarrhea, we may have missed minor cases that occurred between our sampling days. We chose to sample twice weekly to limit the amount of commotion in the barn and thus limit changes in behavior driven by experimenter presence rather than disease. However, sampling daily may have resulted in more calves included in the study.

In conclusion, veal calves that arrive at growing facilities with navel inflammation or diarrhea spend less time lying down compared with those that arrive healthy. This finding suggests that calves with navel inflammation or diarrhea are experiencing pain associated with their condition or are less comfortable lying down on hard, slatted flooring without bedding compared with those that are healthy. Veal producers are encouraged to provide more comfortable lying surfaces for veal calves upon arrival at their growing facilities, particularly those that arrive with conditions such as inflamed navels and diarrhea.

\section{ACKNOWLEDGMENTS}

This project was funded by USDA Animal Health Formula Funds (award no. 2016-36100-06083). Student stipend support was sponsored by the Epperson Research Fellowship. We thank Atlantic Veal and Lamb LLC for providing access to their calves and for their help with data collection. We also thank Brad Hogshead, Elspeth Holder, Deanna Trearchis, Catie Cramer, Holden Hutchinson, and Danielle Coleman from The Ohio State University (Columbus) for their help with data collection. 


\section{REFERENCES}

Bonk, S., O. Burfiend, V. S. Suthar, and W. Heuwieser. 2013. Technical note: Evaluation of data loggers for measuring lying behavior in dairy calves. J. Dairy Sci. 96:3265-3271.

Borderas, T. F., A. M. De Pasillé, and J. Rushen. 2008. Behavior of dairy calves after a low dose of bacterial endotoxin. J. Anim. Sci. $86: 2920-2927$.

Camiloti, T. V., J. A. Fregonesi, M. A. G. von Keyserlingk, and D. M. Weary. 2012. Short communication: Effects of bedding quality on the lying behavior of dairy calves. J. Dairy Sci. 95:3380-3383.

Cyples, J. A., C. E. Fitzpatrick, K. E. Leslie, T. J. DeVries, D. B. Haley, and N. Chapinal. 2012. Short communication: The effects of experimentally induced Escherichia coli clinical mastitis on lying behavior of dairy cows. J. Dairy Sci. 95:2571-2575.

Fecteau, G., J. Pare, D. C. Van Metre, B. P. Smith, C. A. Holmberg, W. Guterbock, and S. Jang. 1997. Use of a clinical sepsis score for predicting bacteremia in neonatal dairy calves on a calf rearing farm. Can. Vet. J. 38:101-104.

Fogsgaard, K. K., C. M. Røntved, P. Sørensen, and M. S. Herskin 2012. Sickness behavior in dairy cows during Escherichia coli mastitis. J. Dairy Sci. 95:630-638.

Fregonesi, J. A., D. M. Veira, M. A. G. von Keyserlingk, and D. M. Weary. 2007. Effects of bedding quality on lying behavior of dairy cows. J. Dairy Sci. 90:5468-5472.
Hart, B. L. 1988. Biological basis of the behavior of sick animals. Neurosci. Biobehav. Rev. 12:123-137.

Johnson, R. W. 2002. The concept of sickness behavior: A brief chronological account of four key discoveries. Vet. Immunol. Immunopathol. 87:443-450.

McGuirk, S. M. 2008. Disease management of dairy calves and heifers. Vet. Clin. North Am. Food Anim. Pract. 24:139-153.

Medrano-Galarza, C., J. Gibbons, S. Wagner, A. M. de Passillé, and J. Rushen. 2012. Behavioral changes in dairy cows with mastitis. J. Dairy Sci. 95:6994-7002

Pempek, J., D. Trearchis, M. Masterson, G. Habing, and K. Proudfoot. 2017. Veal calf health on the day of arrival at growers in Ohio. J. Anim. Sci. 95:3863-3872.

Renaud, D. L., T. F. Duffield, S. J. LeBlanc, S. Ferguson, D. B. Haley, and D. F. Kelton. 2018. Risk factors associated with mortality at a milk-fed veal calf facility: A prospective cohort study. J. Dairy Sci. 101:2659-2668.

Stefanowska, J., D. Swiertstra, A. C. Smits, J. V. van den Berg, and J. H. M. Metz. 2002. Reaction of calves to two flooring materials offered simultaneously in one pen. Acta Agric. Scand. Sect. A $52: 57-64$.

Worth, G. M., K. E. Schütz, M. Stewart, V. M. Cave, M. Foster, and M. A. Sutherland. 2015. Dairy calves' preference for rearing substrate. Appl. Anim. Behav. Sci. 168:1-9. 